\title{
УПРАВЛЕНИЕ РИСКАМИ ПРЕДПРИНИМАТЕЛЬСКОЙ ДЕЯТЕЛЬНОСТИ КАК СПОСОБ ВЫЖИВАНИЯ СУБЪЕКТОВ МАЛОГО И СРЕДНЕГО БИЗНЕСА В УСЛОВИЯХ ЭКОНОМИЧЕСКОГО КРИЗИСА
}

\author{
(C) 2020 Волкодавова Елена Викторовна \\ доктор экономических наук, профессор кафедры менеджмента \\ Самарский государственный экономический университет, Россия, Самара \\ E-mail:vev.sseu@gmail.com \\ (c) 2020 Жабин Александр Петрович \\ доктор экономических наук, профессор, зав. кафедрой менеджмента \\ Самарский государственный экономический университет, Россия, Самара \\ E-mail: apzhabin@yandex.ru
}

\begin{abstract}
В экосистеме каждой страны предприятия малого и среднего бизнеса занимают важное место и имеют поддержку государства для организации и развития своей деятельности. Существующий в настоящее время кризис, вызванный пандемией COVID-19, снижает эффективность и конкурентоспособность деятельности предприятий малого и среднего бизнеса. В статье выявлены ключевые риски деятельности российских предприятий среднего и малого бизнеса. Предлагается разработанный авторами методический подход к управлению рисками в деятельности российских предприятий малого и среднего бизнеса в условиях экономического кризиса. Разработана блок-схема управления рисками, сформулировано содержание этапов ее реализации применительно к особенностям деятельности предприятий малого и среднего бизнеса.
\end{abstract}

Ключевые слова: предприятия малого и среднего бизнеса, неопределенная экономическая среда, риски деятельности, внешние, внутренние, управление рисками

Введение. Проблема управления рисками всегда существовала в практике менеджмента, в т.ч малых и средних предприятий. Но на сегодняшний день, для субъектов малого и среднего бизнеса она звучит особенно остро. Пандемия COVID-19, охватившая многие сегменты геоэкономического пространства, резко ухудшила условия их хозяйственной деятельности.

Для многих предприятий малого и среднего бизнеса на долгое время утеряны рынки сбыта продукции, работ, услуг. Разрывы кооперационных, производственных и сбытовых цепочек привели к потере поставщиков производственных ресурсов: сырья, материалов, комплектующих, оборудования и пр. Остро встала проблема импортозамещения, требующая незапланированных затрат времени и средств на освоение производства импортозамещающей продукции, что для малого и среднего бизнеса в сложившихся экономических условиях практически невозможно. Вынужденная сложившимися обстоятельствами остановка деятельности многих малых и средних предприятий приводит к разрывам как предпринимательских сетей, так и локальных цепочек создания стоимости.
Практически каждое российское предприятие в той или иной мере испытало влияние рисков, связанных с пандемией COVID-19: с закрытием границ между странами первыми среди предприятий малого и среднего бизнеса прочувствовали на себе действие новых рисков предприятия туризма, затем сервиса, а потом и производственные.

Вице-президент ТПП Елена Дыбова на онлайн-конференции ТПП сказала... «Мы оцениваем сейчас, к сожалению, очень высокую цифруоколо 3 млн. предпринимателей могут прекратить свою деятельность, если будут продолжаться такие сложные экономические процессы.» ... «Как показал опрос ТПП в регионах, каждое третье предприятие малого бизнеса отмечает, что при снижении спроса сможет продержаться еще один квартал. Половина их владельцев понимают, что вновь открыть свой бизнес в ближайшее время уже не смогут. Многие могут обанкротиться просто из-за формальных причин, а по закону после банкротства нельзя начать новое дело в течение трех лет, отметила Е.Дыбова [1].

В условиях пандемии COVID-19 среди практически неуправляемых для малых и средних 
предприятий рисков, появились, например, такие, как закрытие таможенных границ между странами для любого вида экономической деятельности, кроме фрагментарных, различных по направленности программ помощи странам друг другу; риски прекращения деятельности, в связи с резким обвалом спроса на рынке.

Влияние рисков, хорошо знакомых предпринимателям и в относительно стабильные времена, в условиях пандемии COVID-19, может быть либо отсрочено во времени, без дальнейших последствий для бизнеса, либо усилено своим деструктивным влиянием в посткризисный период.

Характеристика каждого конкретного вида риска дает представление о возможность изучить особенности и силу его проявления и разработать подход к управлению им.

Правительство России уже разработало ряд действенных мероприятий по поддержке предприятий малого и среднего бизнеса: субсидирование, льготное кредитование, отсрочка уплаты налогов и других платежей. Меры по снижению рисков предпринимательской деятельности применяются и на региональном уровне. Но в сложившихся масштабах рисков деятельности они помогают нивелировать или отсрочивать только часть реальных убытков.

K амортизаторам рисков, следует прежде всего отнести пакет льгот Правительства РФ, уже действующий применительно к малым и средним предприятиям, который отсрочивает влияние ряда ключевых рисков во времени в период карантина, а по некоторым видам - и после него. Этот пакет содержит большой перечень льгот, облегчающий менеджменту малых и средних предприятий управление многими рисками ухудшения хозяйственной деятельности. Среди льгот, отсрочивающих влияние рисков: перенос сроков сдачи отчетности, отсрочка по уплате налогов и взносов, кредитные каникулы, отмена налоговых проверок и взысканий, мораторий на неналоговые проверки, мораторий на возбуждение дел о банкротстве. Среди мер, частично снимающих влияние рисков: реальная безвозмездная помощь каждому сотруднику малых и средних предприятий в размере 12130 руб. в месяц, пониженные тарифы страховых взносов в размере 15 процентов беспроцентный кредит на выплату зарплаты, льготные кредиты малому и среднему бизнесу, возмещение затрат туроператоров, продление действия срочных лицен- зий и иных разрешений.[8] Причем этот, антикризисный для предприятий малого и среднего бизнеса пакет постоянно дополняется новыми льготами.

Методологической и теоретической основой исследования являются:

- метод комплексного анализа, который дал возможность охватить широкий ряд вопросов, проблем и решений в области деятельности российских малых и средних предприятий в условиях нарастания неопределенности экономической среды, и разработать подход к управлению рисками в кризисной экономической среде, вызванной пандемией COVID-19;

- метод системного анализа, с помощью которого исследованы вопросы взаимосвязи и взаимозависимости влияния предпринимательских рисков на деятельность малых и средних предприятий;

- концепция рационального поведения рыночных субъектов, принципы которой позволили выполнить типологию актуальных для малых и средних предприятий рисков, требующих учета и управления в условиях кризисной среды, сформировать методический подход к их управлению.

Экспериментальная база исследования предпринимательская деятельность российских малых и средних предприятий в условиях пандемии COVID-19.

Результаты. Структура предпринимательских рисков очень обширна и насчитывает множество видов, которые систематизированы российскими учеными и практиками по различным классификационным признакам. В отечественной литературе представлены различные подходы к их классификации, например, в [3, 5, 6] и управлению, например, [2, 4, 7, 9, 10].

В сложившейся для российских малых и средних предприятий экономической кризисной ситуации, авторы данной статьи считают необходимым сделать акцент на внешнеэкономических, внутриэкономических и внутриорганизационных рисках.

К внешнеэкономическим, прежде всего, необходимо отнести все многообразие рисков, связанных с реализацией экспортных, импортных, кооперационных контрактов и операций по импортозамещению товаров, работ, услуг. Для предприятий малого и среднего бизнеса основная масса внешнеэкономических операций, как правило происходит, в рамках стран Евра- 
зийского экономического союза (ЕАЭС), таможенного союз ЕАЭС, Содружества Независимых Государств (СНГ), характеризующихся льготными режимами осуществления торговых операций. Но в условиях пандемии COVID-19 и эти зоны льготной торговли стали для предприятий малого и среднего бизнеса высокорисковыми.

Ко внутриэкономическим рискам, авторы статьи относят внутристрановые, региональные и отраслевые риски.

K внутристрановым, отраслевым и региональным рискам авторы относят все риски, связанные с ухудшением условий хозяйственной деятельности внутри страны и региона регистрации малого или среднего предприятия; разрывы межрегиональных поставок продуктов, работ, услуг в рамках их кооперационной или торговой деятельности; нарушение межотраслевых пропорций производства и поставок продукции как конечным потребителям, так и смежным отраслям.

К внутриорганизационным рискам авторы относят неспособность адаптации отдельных или всех элементов существующей бизнесмодели малого или среднего предприятия к изменениям бизнес-среды. От степени управления внутриорганизационными рисками зависит выживаемость каждого конкретного предприятия. В одних и тех же кризисных условиях одни предприятия отрасли разоряются, а другие, где сильный менеджмент, высокое качество и конкурентоспособность продукции, запас рентабельности по издержкам и прибыли, не только не разоряются, а наоборот, находят новые возможности для развития своего бизнеса.

В сложившейся для предприятий малого и среднего бизнеса кризисной экономической ситуации, возникает потребность выработки актуальных предпринимательских компетенций по выявлению новых возможностей для адаптации бизнеса к кардинальным изменениям бизнессреды. И прежде всего, к управлению вновь возникшими предпринимательскими рисками и теми, чье отсроченное действие может усугубить пандемия COVID-19.

Для формирования эффективной системы управления рисками, прежде всего, необходимо установить их качественные параметры: вид и направленность действия, размер возможного убытка от их возникновения.

В зависимости от качественного проявления и влияния на результаты деятельности малых и средних предприятий каждой из групп риска, по мнению авторов, нужно рассматривать три важных аспекта процесса управления рисками.

Первый аспект управления зависит от выявления места их возникновения, согласно которому дифференцируем риски, которые действуют на внутреннем и внешнем рынках, а также внутриорганизационные риски предприятий.

Второй аспект управления зависит от времени возникновения рисков. Здесь авторы выделяют:

- риски неизвестные, с которыми предприятия столкнулись впервые;

- известные, действие которых ограниченно временем карантина;

- известные, действие которых отсрочено введением мер поддержки малого и среднего бизнеса, но будет пролонгировано и усилится в посткарантинный период.

И третий аспект: дифференциация рисков на управляемые, которые возможно нивелировать или ослабить и неуправляемые, которые нивелировать управленческим воздействием не представляется возможным. Исходя из этих теоретических положений, авторы статьи разработали методический подход к управлению рисками малых и средних предприятий в условиях деятельности в кризисной среде, представленный в блок-схеме 1.

1. Вначале необходимо из всего многообразия предпринимательских рисков выявить те, которые имеют влияние на функционирование данного конкретного предприятия с учетом вида, бизнес-процессов и масштаба его деятельности, ресурсов, которые необходимы для производства продукции, работ, услуг и объемов их реализации в каждом сегменте рынка.

2. Необходимо определить вероятность наступления каждого из выявленных рисков. Этот анализ проводится методом теории вероятности и математической статистики.

3. Далее все выявленные риски необходимо дифференцировать на управляемые и неуправляемые.

4. Для того, чтобы определить силу влияния каждого из выявленных рисков, на деятельность данного предприятия, необходимо оценить изменения каждого ключевого показателя деятельности предприятия под влиянием каждого риска.

5. Затем, оценив локальный ущерб под влиянием наступления наиболее вероятных ри- 


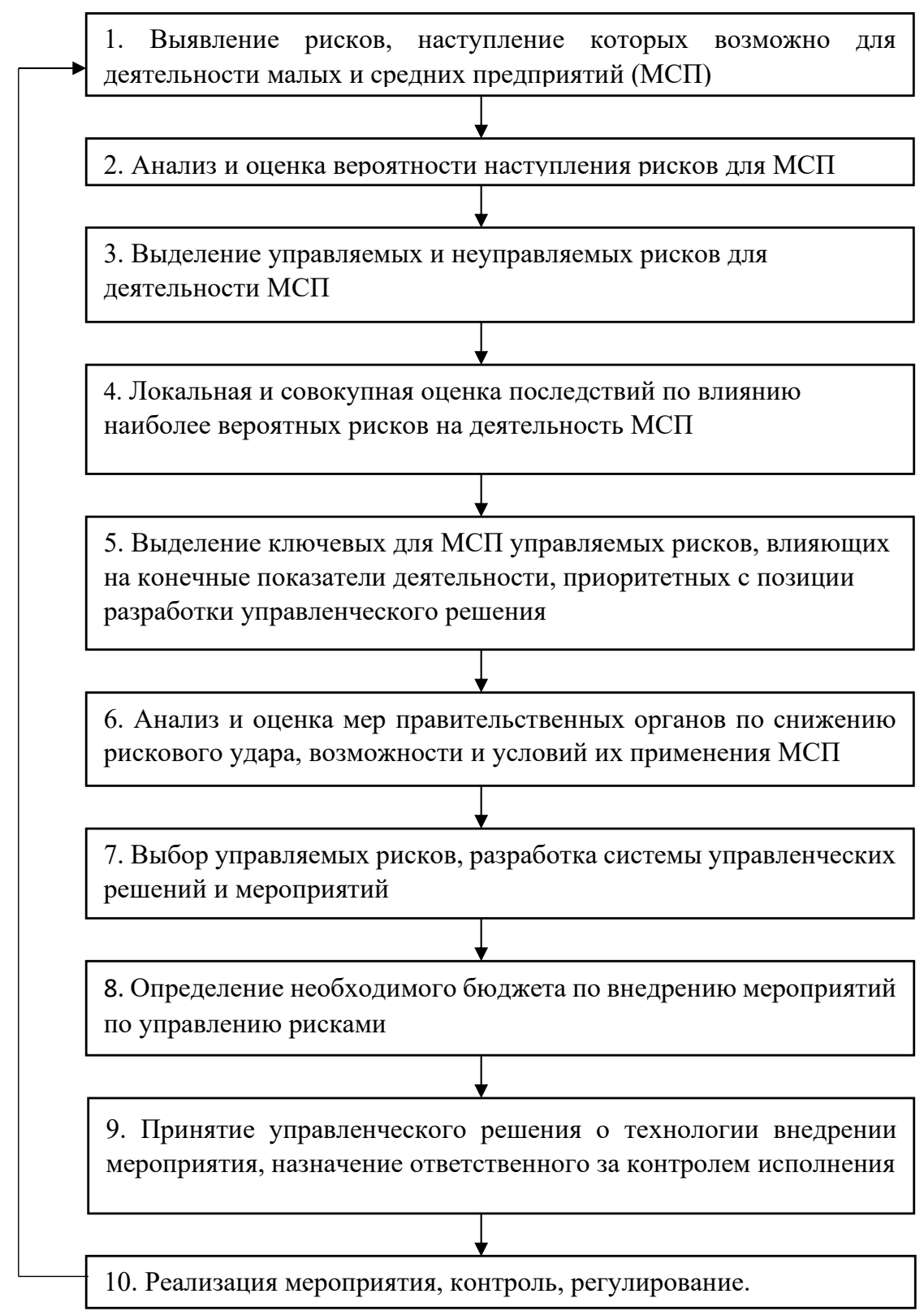

Рис. 1 Блок-схема методического подхода к управлению рисками малых и средних предприятий.

сков, необходимо ранжировать риски по силе проявления на конечные показатели предприятия. Выявить, какие риски для бизнеса данного предприятия считаются важнейшими, насколько они связаны с другими рисками.

6. Необходимо установить какие меры, разработанные правительственными органами по снижению рискового удара, и на каких условиях возможно применить в рамках данного малого или среднего предприятия.

7. Следующий этап предполагает разработку системы управленческих решений и соответствующих каждому из них мероприятий по нивелированию действия управляемых рисков. Согласны с Костиным К.Б. и Кожухиной К.А. [7], что в практике менеджмента к основным методам снижения управляемых рисков, относятся: уклонение от риска, передача риска, локализация риска, распределение (диверсификации) риска, компенсация риска. Выбор метода управления минимизацией риска должен принимать менеджмент предприятия на основе взвешенного решения с учетом результата всех вышеперечисленных этапов.

8. Затем необходимо определить средства, необходимые для внедрения каждого меропри- 
ятия и совокупный бюджет.

9. На следующем этапе необходима разработка технологии по внедрению каждого из намеченных к реализации мероприятий и назначение ответственного за контролем исполнения их внедрения.

10. На последнем, самом ответственном этапе, осуществляется внедрение разработанных мероприятий и постоянный контроль ответственного лица за ходом и результатами внедрения. В случае отклонений в ходе внедрения мероприятий по снижению выявленных рисков, ведется постоянный мониторинг рисков на рынке. И если выявляются новые риски, оказывающие существенное влияние на деятельность данного предприятия, к ним применяется данный методический подход, разрабатываются и принимаются соответствующие управленческие решения.

Заключение. Перед менеджментом российских малых и средних предприятий встала задача выживания в условиях кризиса, вызванного пандемией COVID-19. Для каждого из них сейчас важно найти единственно правильный способ выживания в этих сложных экономических условиях. Поэтому задача менеджмента выбрать и внедрить тот подход к управлению рисками, который позволит максимально адаптировать существующую бизнес-модель к условиям нарастающей неопределенности, чтобы в текущем и стратегическом периодах сохранить конкурентоустойчивость текущей деятельности и найти новые возможности для дальнейшей деятельности в существующих и новых сегментах рынка. В отечественной литературе существует много подходов к управлению предпринимательскими рисками. Один из них, позволяющий найти обоснованный выход из кризисной ситуации с помощью эффективного управления рисками, предложен авторами данной статьи. Его применение позволит предприятиям выявить ключевые риски деятельности предприятий и оперативно отреагировать на угрозы, возникающие от их влияния.

\section{Библиографический список}

1. Агеева О. ТПП предупредила о риске разорения 3 млн. предпринимателей из-за вируса. Информационное агентство «РБК». Ежедневная деловая газета РБК [Электронный ресурс].URL https://www.rbc.ru/economics/2 1/03/2020/5e7490569a7947467949c77d (дата обращения 25 .04.2020)

2. Акмайкин В.М., Газетдинов М. Х., Гарафеев Р. К. Управление предпринимательскими рисками - выделение доминирующего фактора риска. Ученые записки Российской Академии предпринимательства. 2015 . № 44. С. 14-22.; Вдовина Ю.С., ВолкодавоваЕ.В. Управление рисками организационных изменений в нефтегазовой отрасли. Инновационная деятельность. 2019. № 2 (49). С. 13-22.

3. Волкодавова E.В., ХанбиковаЛ.В.Классификация рисков как инструмент подсистемы управления бизнеспроцессами внешнеэкономической деятельности промышленных предприятий. Вестник Самарского государственного экономического университета. 2013. № 4 (102). С. 26-29.

4. Глазкова И.Н., Газизуллин Н. Ф.Принципы формирования системы риск-менеджмента и контуры модели управления предпринимательскими рисками. Проблемы современной экономики. 2014. № 3 (51). С. 159161.

5. Ермолаев Д. Н. Место рисков контрагентов в системе предпринимательских рисков. Современные тенденции в экономике и управлении: новый взгляд. 2011. № 11-2. С. 113-119.

6. Киселева И.А., Симонович Н.Е. Оценка рисков в бизнесе: предпринимательские риски.Финансовая аналитика: проблемы и решения. 2017. Т. 10. № 3 (333). С. 244-257.

7. Костин К.Б., Кожухина К.А. Проблемы совершенствования управления рисками в предпринимательской деятельности. Научный журнал НИУ ИТМО. Серия Экономика и экологический менеджмент № 1,2019 c. $171-180$

8. Льготы для малого и среднего бизнеса в связи с коронавирусом. Главбух 20 апреля 2020 г. [Электронный ресурс]. URL: https://www.glavbukh.ru/art/99651-lgoty-dlya-malogo-i-srednego-biznesa-v-svyazi-skoronavirusom-v-2020-godu: (дата обращения 26. 04.2020)

9. Разинкина И.В., Жукова А. Ю. Предпринимательские риски: понятие, виды, пути минимизации воздействия. В сборнике: Развитие инновационной экономики: достижения и перспективы материалы VI международной научно-практической конференции. 2019. С. 336-342.

10. Сибирко И., Охотников И.Риск-менеджмент: модель эффективного управления предпринимательскими рисками. Предпринимательство. 2014. № 1. С. 146-151.

11. Ящук Е.И. Формы предпринимательского бизнеса и предпринимательский риск. Образование и наука без границ: социально-гуманитарные науки. 2015. № 2. С. 83-85. 